\title{
Using Physical Education Courses to Help Increase Well-Being of RN-BSN Nursing Students: An Exploratory Analysis of Outcomes
}

\author{
John E. Lothes II, LPA, Ed.D., LPA \\ University of North Carolina Wilmington \\ School of Health and Applied Human Sciences \\ Debra A. Hrelic, Ph.D. RNC \\ University of North Carolina Wilmington \\ School of Nursing \\ Amy Olsen, M.A. \\ University of North Carolina Wilmington \\ School of Health and Applied Human Sciences
}

\begin{abstract}
Background: Student health and wellness has been a growing concern over the years. Evidence is showing that behaviors and health patterns developed in college tend to hold through the years after graduation.

Aim: To examine the pre-post wellness outcomes of nursing students taking a physical education course in an online accelerated Registered Nurse-Bachelor of Science Nursing (RN-BSN) program at a university in the Southeast region of the United States.

Methods: An online course with incorporated physical activities and tutorials was designed based on the Travis Wellness Inventory to teach about 12 different dimensions of wellness. Students completed modules that addressed different aspects of wellness. Wellness was assessed using the Wellness Inventory and pre-post outcomes were examined.

Results: The results found statistically significant changes between the pre and post assessments for all dimensions of wellness outcomes. There were also significant changes between the pre and post assessments when investigating differences based on gender with females improving on all 12 dimensions and males on 4.
\end{abstract}

Conclusion: Introductory Physical Education (PED101) courses may be useful in improving wellness and reducing stress and turnover for RN-BSN students.

Submitted 27 January 2020: accepted 1 June 2020

Keywords: health education, mental health, wellness, stress, physical education

Attending college is recognizably a stressful event, particularly for non-traditional adult online accelerated students returning to college for a second degree (Osam, Bergman \& Cumberland, 2017). In the case of RNs who return to school for their bachelor's degree, RN-BSN students, stress may be further enhanced. The decision to advance or 
pursue higher education may have been mandated by professional employment requirements such as established time limits for attaining a BSN degree, or the changing demands of the prevailing job market to avoid termination. Domestic responsibilities and dependents present additional stressors while trying to strike the balance between work and study.

Research often refers to the excessive workload experienced by full time Registered Nurses (RN) who frequently report feeling overworked and understaffed. For many RNs, overtime, and non-social weekend and holiday hours are the norm (Happell, Dwyer, Reid-Searl, Burke, Caperchione, Gaskin, 2013). Nurses typically care for high acuity patients, dealing with life and death scenarios on a daily basis, while also tending to pressures within their own family situations at home. They are being pulled in a multitude of directions, any of which might be overwhelmingly stressful on any given day. The stress of returning to school may present additional financial burdens due to educational costs extending beyond that of any tuition reimbursement offered by employers (Perfeto, 2015; Sarver, Cichra, \& Kline, 2015).

The return to school may be further complicated by a syllabus that includes exams, written assignments, discussion boards, deadlines, and use of computers and technology in ways the student had never imagined. This may lead to additional stress and interference with optimal levels of concentration, memory retention, and problem-solving ability. In work related or academic situations, retention and progression may drastically be affected by these stress related issues (Beauvais, Stewart, DeNisco \& Beauvais, 2014; Terp, Hjarthag \& Bisholt, 2019). A nurse’s primary professional responsibility is to care for others. Unfortunately, self-care in nursing is often only minimally considered or overlooked entirely (Crane \& Ward, 2016; Drew et al., 2016). It has long been touted that physical exercise of many different forms may play a part in stress reduction and overall physical wellness (Ferkel, Judge, Stodden, \& Griffin, 2014; Warren, Odenheimer Brin, 2017; American College Health Association, 2010). The purpose of this study is to examine the effect of physical education courses on the wellbeing of RN-BSN students to determine whether such courses increase wellness.

\section{BACKGROUND}

Stress has been linked to both acute and chronic illness for many years. Most recently stress has become recognized as a cause of mood changes, cognition disturbances, and having a negative impact on academic success (Terp, et al., 2019). In 2014, the American College Health Association (ACHA, 2010, 2019) National Health Assessment II: Reference Group Data Report confirmed that college life is stressful, for both traditional and non-traditional students. The study found that over $47 \%$ of college students reported academic pursuits to be "traumatic or very difficult to handle", while approximately 55\% reported them to cause "more than average stress" (ACHA, 2010, 2019). In 2018, the ACHA-National Health Assessment II: Reference Group Data Report yielded even more concerning results. In the previous 12 months, $90.7 \%$ of students felt overwhelmed while $67.3 \%$ of students reported their overall level of stress to be more than average or "tremendous" (ACHA, 2019).

A high level of stress has been shown to inhibit the integration of new information and the utilization of prior knowledge. By decreasing stress levels and improving overall wellness these negative effects on cognition may be mitigated (Terp, Hjarthag \& Bisholt, 2019). Stress has been shown to have a critical impact on human memory, specifically in educational contexts. It prevents a person's ability to benefit from prior knowledge during learning and to build upon it. Chronic life stress may have a detrimental effect on learning and coping. When new knowledge and 
material is directly related to or linked with an event that stands out in a person's memory, due to the stress of the event, it is more likely to be remembered in the long run. Research demonstrates a negative correlation between stress and learning in nurses within academic and clinical settings (Beauvais, Stewart, DeNisco \& Beauvais, 2014; Terp, Hjarthag \& Bisholt, 2019). The observed effects of educating nurses in self-care techniques and stress relief include positive patient care outcomes and enhanced nurse effectiveness (Crane \& Ward, 1981).

Stress is not a problem unique to nursing or to college students. In an effort to promote wellbeing in all professions and walks of life, Travis (1981) developed a Wellness Inventory. Travis regards wellness as a dynamic ever-changing process, not a static state. Varying degrees of wellness and illness are captured by the wellness paradigm. The goal for nursing professionals is to continually move towards increasing levels of wellness while engaging in behaviors that manage emotional states, such as stress (Well People, 2018a). Well People (2018a) expressed this sentiment by stating the following:

"High-level wellness involves giving good care to your physical self, using your mind constructively, expressing your emotions effectively, being creatively involved with those around you, and being concerned about your physical, psychological and spiritual environments. In fact, it's less important where you are on the continuum; it's more important which direction you're facing - toward illness or wellness."

\section{METHODS}

\section{Research Objectives}

The overall research question addressed by this study asks whether wellness education affects wellness scores in RNBSN nursing students taking the PED101 course. While this study was exploratory in nature, hypotheses were made before the pre-post assessment data collections of the wellness inventory from the beginning of the semester to the end of the semester. Based on previous physical education, wellness inventory research with traditional college students (Lothes, 2020), we hypothesized that wellness scores would increase for RN-BSN students after taking PED101 in an online accelerated program format. The hypotheses about increased wellness include:

$\mathrm{H}_{1}$ : Overall wellness scores in all 12 dimensions would show statistically significant increases from the beginning to the end of the course for all RN-BSN students.

$\mathrm{H}_{2}$ : Overall wellness scores in all 12 dimensions would show statistically significant increases from the beginning of the course to the end of the course for male RN-BSN students.

$\mathrm{H}_{3}$ : Overall wellness scores in all 12 dimensions would show statistically significant increases from the beginning of the course to the end of the course for female RN-BSN students.

Gender differences for overall wellness scores at pre-post were not hypothesized but were examined post hoc.

\section{Participants and Design}

The research adopted a quantitative comparative within-subjects design. Non-traditional RN-BSN online accelerated Nursing students $(\mathrm{N}=136)$ taking PED 101 were assessed at the beginning of the semester (January, 2018) for each dimension of wellness and then again at the end of the semester (May, 2018) for a pre-post assessment of wellness. The courses were online with tutorials built into Blackboard (Blackboard, n.d.) and Tophat (Nanney, 2019), for students to work through. Each class was a two-credit online course designed to meet the expectation of 150 minutes 
per week for physical activity recommended by the National Guidelines for Physical Activity for American 2018 (US Department of Health and Human Services, 2018). Students would submit evidence of their exercise in a variety of formats from journals, to online logging of activity, to pictures of them at the gym, or attending some form of fitness class. Each class incorporated a lab component delivered via Tophat and the Wellness Inventory (Travis, 1981; Travis, 2004; Well People, 2018b) assignments delivered via Blackboard. Tophat is a library of interactive college textbooks that students may access and read on mobile devices as well as computers. The platform was designed for teachers to check attendance with additional products for student engagement, providing assignments for students and interactive labs and activities for students to access either in or out of class.

Each week there were online learning modules from the wellness inventory about one of the 12 dimensions of wellness. The 12 dimensions of wellness are self-responsibility and love, breathing, sensing, eating, moving, feeling, thinking, playing and working, communicating, intimacy, finding meaning and transcending. There was no deviation for start time or due dates of assignments for the online wellness inventory. Students taking the PED 101 course were allowed access to the Wellness Inventory online and its tutorial materials and were expected to engage in an assigned number of wellness activates for each module.

\section{Course Description (Intervention)}

The university description for the PED 101, 2 credit course is: Physical Participation in physical activity, increased awareness and development of the physical, spiritual, emotional, social, and intellectual components of wellness, becoming an informed health consumer, and the application of healthy lifestyle choices for improved quality of life. The PED 101 class meets the University Studies Lifespan Wellness requirement, which includes Physical Activity and Wellness, a 2-credit university studies course required of all students. The purpose of this course is threefold: 1) to provide students with instruction and guidance for participation in lifetime physical activities (i.e. cardiovascular, resistance, and flexibility) to improve student fitness, health, and wellness; 2) to recognize the multidimensional nature of wellness and its overlapping components; and 3) to enhance self-awareness and self-management skills associated with lifelong wellness. Course activities and assignments are specifically designed to improve students' knowledge, thoughts, motivations, skills, and behaviors to aid in their lifetime journey toward higher levels of wellness regardless of classification (traditional or non-traditional).

\section{Data Collection - Wellness Inventory}

The Wellness Inventory (Travis, 2004; Well People, 2018b) was utilized to gather data at the start and end of the semester to assess overall student ratings on the 12 dimensions of wellness. The Wellness Inventory is both reliable and valid in the assessment of overall college student population wellness; the inventory also has a strong internal consistency and content validity (Palombi, 1992). The Wellness Inventory has been a suggested instrument for use in clinical medical settings (Bart et al., 2018). The Wellness Inventory's assessment parameters also fit with the World Health Organization's (WHO, 2000) operational definition of health, "Wellness is the optimal state of health of individuals and groups. There are two focal concerns: the realization of the fullest potential of an individual physically, psychologically, socially, spiritually, and economically, and the fulfillment of one's roles and expectations in the family, community, place of worship, and other settings." 
The Wellness Inventory has been used with college populations (Palombi, 1992) and addresses the concerns of the WHO's (2000) suggestions on helping move people towards a more holistic approach to wellness. Twelve dimensions form the Travis Wellness Inventory. These are fundamental life processes that interact with each other to shape life experiences and may help create a state of personal wellbeing. They include self-responsibility and love, breathing, sensing, eating, moving, feeling, thinking, playing and working, communicating, intimacy, finding meaning, and transcending (Well People, 2018b). The Wellness Inventory is used as both an assessment and educational tool for individuals to learn about and change their levels of wellness. The Wellness Inventory was used as part of a physical education class at university in the southeast United States.

The Wellness Inventory asks questions on a 10-point Likert scale, ranging from 0 (lowest) to 10 (highest) ratings about the 12 dimensions of wellness. After completing the assessment, an outcome score is generated based on a total of all the scores ( 0 being lowest and 100 being highest for each dimension). For a more thorough and detailed explanation of each wellness inventory dimension see Lothes (2020), Travis (1981) and Travis (2004).

\section{Statistical Analysis}

To analyze the data, we used descriptive statistics to compute for gender and overall wellness scores from pre to postassessment. Analysis of variance (ANOVA) was used to assess any statistical changes in overall ratings of wellness and by gender to see if changes occurred from the start to end of the PED course.

\section{RESULTS}

\section{Demographics}

The demographic breakdown of participants by gender and age were as follows. Gender breakdown was Male $=14$, Female $=122$, other $=0$, Total $=136$. The breakdown by age was $45+=24,35-44=45,25-34=54,18-24=13$, Total $=136$. Mean ages were not available, the Wellness Inventory does categorical collection of age groups.

\section{Overall Wellness Scores}

Pre-post assessment of all the pre-post data showed significant increases in all 12 dimensions of wellness using twotailed probability levels: Self-Responsibility $\mathrm{F}(1,228)=65.11, \mathrm{p}<.0001, \mathrm{~d}=1.06$., Breathing $\mathrm{F}(1,228)=113.54$, $\mathrm{p}$ $<.0001, \mathrm{~d}=1.42$, Sensing $\mathrm{F}(1,228)=69.28, \mathrm{p}<.0001, \mathrm{~d}=1.10$, Eating $\mathrm{F}(1,228)=66.07, \mathrm{p}<.0001, \mathrm{~d}=1.09$, Moving $\mathrm{F}(1,228)=142.17, \mathrm{p}<.0001, \mathrm{~d}=1.59$, Feeling $\mathrm{F}(1,228)=80.10, \mathrm{p}<.0001, \mathrm{~d}=2.09$, Thinking $\mathrm{F}(1,228)$ $=84.81, \mathrm{p}<.0001, \mathrm{~d}=1.24$, Playing and Working $\mathrm{F}(1,228)=87.52, \mathrm{p}<.0001, \mathrm{~d}=1.23$, Communicating $\mathrm{F}(1,228)$ $=23.01, \mathrm{p}<.0001, \mathrm{~d}=.64$, Intimacy $\mathrm{F}(1,228)=33.91, \mathrm{p}<.0001, \mathrm{~d}=.77$, Finding Meaning $\mathrm{F}(1,228)=52.18, \mathrm{p}<$ $.0001, \mathrm{~d}=.97$, Transcending $\mathrm{F}(1,228)=44.74, \mathrm{p}<.001, \mathrm{~d}=.90$. 
Table 1: Overall Wellness Scores Pre/Post

\begin{tabular}{|l|l|l|l|l|}
\hline \multirow{2}{*}{ Dimension } & \multicolumn{2}{|l|}{$\begin{array}{l}\text { PRE } \\
\text { (N = 136) }\end{array}$} & \multicolumn{2}{l|}{$\begin{array}{l}\text { Post } \\
\text { (N = 136) }\end{array}$} \\
\cline { 2 - 5 } & Mean & SD & Mean & SD \\
\hline $\begin{array}{l}\text { Self- } \\
\text { Responsibility } \\
\text { \& Love }\end{array}$ & 71.30 & 11.09 & $82.71^{* * *}$ & 10.29 \\
\hline Breathing & 55.17 & 17.68 & $78.14^{* * *}$ & 14.64 \\
\hline Sensing & 66.37 & 12.68 & $80.10^{* * *}$ & 12.24 \\
\hline Eating & 56.14 & 16.99 & $73.59^{* * *}$ & 14.88 \\
\hline Moving & 49.87 & 21.72 & $78.53^{* * *}$ & 13.41 \\
\hline Feeling & 62.00 & 14.70 & $77.89^{* * *}$ & 11.96 \\
\hline Thinking & 62.56 & 13.63 & $78.82^{* * *}$ & 12.47 \\
\hline $\begin{array}{l}\text { Playing } \\
\text { Working }\end{array}$ & 58.98 & 15.55 & $77.36^{* * *}$ & 14.26 \\
\hline Communicating & 76.68 & 11.02 & $83.85^{* * *}$ & 11.11 \\
\hline Intimacy & 77.14 & 13.54 & $86.54^{* * *}$ & 10.49 \\
\hline $\begin{array}{l}\text { Finding } \\
\text { Meaning }\end{array}$ & 66.65 & 13.39 & $79.39^{* * *}$ & 13.00 \\
\hline Transcending & 65.53 & 15.18 & $78.86^{* * *}$ & 14.53 \\
\hline$* 01 * *<001, * * * * .0001$ & & & \\
\hline
\end{tabular}

$*<.01, * *<.001, * * *<.0001$

\section{Gender Differences}

Gender did not significantly affect any of the 12 dimensions of wellness from the start (pre-assessment) to end (postassessment) of the course.

For pre-post assessment of males, the results showed significant increases for Breathing $\mathrm{F}(1,26)=9.84, \mathrm{p}<.004$, $\mathrm{d}=1.29$; Moving $\mathrm{F}(1,26)=7.87, \mathrm{p}<.009, \mathrm{~d}=1.17$; Feeling $\mathrm{F}(1,26)=6.62, \mathrm{p}<.02, \mathrm{~d}=0.95$; and Thinking $\mathrm{F}(1$, 26) $=11.33, \mathrm{p}<.002, \mathrm{~d}=1.55$. 
Table 2: Males Wellness Scores Pre/Post

\begin{tabular}{|l|l|l|l|l|}
\hline \multirow{2}{*}{ Dimension } & \multicolumn{2}{l|}{$\begin{array}{l}\text { Male-Pre } \\
\text { (N = 14) }\end{array}$} & \multicolumn{2}{l|}{$\begin{array}{l}\text { Male-Post } \\
\text { (N = 14) }\end{array}$} \\
\cline { 2 - 5 } & Mean & SD & Mean & SD \\
\hline $\begin{array}{l}\text { Self- } \\
\text { Responsibility } \\
\text { \& Love }\end{array}$ & 72.15 & 8.93 & 79.62 & 9.61 \\
\hline Breathing & 53.23 & 17.22 & $72.69^{* *}$ & 11.83 \\
\hline Sensing & 72.08 & 10.53 & 77.77 & 12.68 \\
\hline Eating & 61.00 & 17.48 & 70.08 & 12.44 \\
\hline Moving & 57.08 & 18.79 & $75.23^{* *}$ & 10.35 \\
\hline Feeling & 61.46 & 13.70 & $75.23^{*}$ & 11.00 \\
\hline Thinking & 60.23 & 11.71 & $77.15^{* *}$ & 10.78 \\
\hline $\begin{array}{l}\text { Playing } \\
\text { Working }\end{array}$ & 63.00 & 13.32 & 73.46 & 12.00 \\
\hline Communicating & 78.00 & 11.98 & 80.15 & 11.23 \\
\hline Intimacy & 77.62 & 10.63 & 84.54 & 9.30 \\
\hline $\begin{array}{l}\text { Finding } \\
\text { Meaning }\end{array}$ & 65.00 & 13.43 & 74.85 & 12.50 \\
\hline Transcending & 61.46 & 14.86 & 72.69 & 15.33 \\
\hline$*<01, * *<001, * * *<.0001$ & & & \\
\hline
\end{tabular}

$*<.01, * *<.001, * * *<.0001$

For pre-post assessment of females, the results showed significant increases in all 12 dimensions of wellness: SelfResponsibility $\mathrm{F}(1,200)=31.24, \mathrm{p}<.0001, \mathrm{~d}=.14$; Breathing $\mathrm{F}(1,200)=104.12, \mathrm{p}<.0001, \mathrm{~d}=1.45$; Sensing $\mathrm{F}(1$, $200)=69.84, \mathrm{p}<.0001, \mathrm{~d}=1.28$; Eating $\mathrm{F}(1,200)=65.75, \mathrm{p}<.0001, \mathrm{~d}=1.19 ;$ Moving $\mathrm{F}(1,200)=136.46, \mathrm{p}<$ $.0001, \mathrm{~d}=1.63$; Feeling $\mathrm{F}(1,200)=73.28, \mathrm{p}<.0001, \mathrm{~d}=3.39$; Thinking $\mathrm{F}(1,200)=73.70, \mathrm{p}<.0001, \mathrm{~d}=1.18$; Playing and Working $\mathrm{F}(1,200)=86.14, \mathrm{p}<.0001, \mathrm{~d}=1.29$; Communicating $\mathrm{F}(1,200)=24.94, \mathrm{p}<.0001, \mathrm{~d}=0.73$; Intimacy $\mathrm{F}(1,200)=32.10, \mathrm{p}<.0001, \mathrm{~d}=.079$; Finding Meaning $\mathrm{F}(1,200)=76.69, \mathrm{p}<.0001, \mathrm{~d}=1.00$; and Transcending $\mathrm{F}(1,200)=41.89, \mathrm{p}<.001, \mathrm{~d}=0.96$. 
Table 3: Females Wellness Scores Pre/Post

\begin{tabular}{|l|l|l|l|l|}
\hline \multirow{2}{*}{ Dimension } & \multicolumn{2}{|l|}{$\begin{array}{l}\text { Female-Pre } \\
\text { (N = 122) }\end{array}$} & \multicolumn{2}{l|}{$\begin{array}{l}\text { Female-Post } \\
\text { (N = 122) }\end{array}$} \\
\cline { 2 - 5 } & Mean & SD & Mean & SD \\
\hline $\begin{array}{l}\text { Self- } \\
\text { Responsibility } \\
\text { \& Love }\end{array}$ & 71.11 & 11.40 & $83.1 * * *$ & 10.45 \\
\hline Breathing & 55.28 & 17.81 & $78.93^{* * *}$ & 14.81 \\
\hline Sensing & 65.65 & 12.84 & $80.66^{* * *}$ & 12.22 \\
\hline Eating & 55.51 & 17.00 & $74.29^{* * *}$ & 15.32 \\
\hline Moving & 48.78 & 22.01 & $78.88^{* * *}$ & 13.68 \\
\hline Feeling & 61.91 & 14.87 & $78.13^{* * *}$ & 12.10 \\
\hline Thinking & 62.95 & 13.91 & $79.11^{* * *}$ & 12.81 \\
\hline $\begin{array}{l}\text { Playing } \\
\text { Working }\end{array}$ & 58.18 & 15.61 & $77.82^{* * *}$ & 14.55 \\
\hline Communicating & 76.49 & 10.98 & $84.14^{* * *}$ & 10.98 \\
\hline Intimacy & 76.93 & 13.90 & $86.73^{* * *}$ & 10.68 \\
\hline $\begin{array}{l}\text { Finding } \\
\text { Meaning }\end{array}$ & 66.83 & 13.49 & $80.01^{* * *}$ & 13.14 \\
\hline Transcending & 66.20 & 15.20 & $79.52^{* * *}$ & 14.30 \\
\hline
\end{tabular}

$*<.01, * *<.001, * * *<.0001$

\section{DISCUSSION}

Throughout participation in this course, RN-BSN students took part in a variety of activities and exercises as part of the online learning modules and the wellness inventory. They participated in an assigned number of wellness activities each week for every module. The dimensions addressed in the wellness inventory, as previously described, impacted many levels of cognitive, emotional and physical wellness.

The threefold purpose of this course was achieved. Students were provided instruction and guidance in participation of lifetime physical activity, such as cardiovascular, resistance and flexibility exercises. Incorporation of this type of activity into one's life has been shown to improve fitness, health and wellness. The nature of wellness is multidimensional, and its many components overlap and intertwine. The physical, spiritual, emotional, social and intellectual aspects of wellness were well presented in PED 101 and the 12 dimensions of the wellness inventory. The last aspect of the purpose was to affect the self-awareness and self-management skills that align with lifelong wellness. By improving participant knowledge and practice in these areas, the goal of assisting students to learn and perform health behaviors, which if they continue, will lead to lifelong wellness activities, was evidenced.

Gender differences were also examined in this study to see if there were not only pre and post-differences between male and female students, but also see if changes occurred within these demographics for pre and post-assessments. 
Interestingly, males and females statistically were the same at pre and post-assessment. While females showed significant increases in all 12 dimensions of wellness, males only showed significant increases in 4 dimensions (Breathing, Moving, Thinking, and Feeling) from pre to post-assessment. One possible explanation for this is the small number $(N=14)$ of males in this study. Small sample groups require more pronounced changes to be significantly different than a larger sample group, like the females. Of note, is that all male scores did show increases in pre to post scores, even though they were not statistical significant.

While we cannot assume that the wellness inventory and Online Accelerated Program (OAP) tutorials caused these changes to occur, the results do suggest that pre-post score changes may be influenced by students taking a PED101 course in a nursing OAP program. As Warren and Odenheimer (2017) discuss the need to increase physical activity at the collegiate level, Ferkel et al. (2014) have also expressed concerns about factors of wellness and physical education suggesting a closer examination of factors which will increase physical activity and physical fitness. This study has addressed these concerns by addressing both typical health outcomes in the Moving and Eating dimensions as well as ten other dimensions of wellness. The results from this study show that nursing students, even in an OAP program, may show benefits and changes in health and wellbeing outcomes if afforded the opportunity to take classes that address issues of wellness.

These factors are important in the lifelong journey of wellness, especially in a group of individuals embarking on a career in health care. These results also show that male and female students may show benefits and increased wellness ratings as a result of taking an online physical education course. It is recommended that if schools are going to adopt an online or face-to-face physical education course, that issues of health and wellness beyond that of exercise and diet be addressed in the class.

Informal qualitative responses also support the importance of teaching self-care to future nurses. Comments from students about the course and outcomes of learning about wellness based on the 12 dimensions of the wellness inventory included:

"the true meaning behind this class, (was) personal awareness. I think this class was to make us reflect (sic) on where we were at with our wellness and how we could positively influence it."

Many students saw the wellness inventory as a path to "learning more about myself', while others were motivated to "care for my body both physically, with exercise and food, and also mentally and spiritually." The course was frequently described as one "that really centered on wellness and emotional/physical wellbeing." In particular, participants singled out "the breathing and meditation" dimensions as having been "very helpful during this stressful semester", stating that "I am sure I will continue to use them!!"

As mentioned earlier, nursing is a stressful career and there are many obstacles that nursing students face when returning to school. Another student elaborated on this topic,

"I did not know what to expect with this course but it helped me to engage in areas that I did not pay attention to such as focusing on my breathing. Meditating is a great way tocalm yourself and reduce stress. Time is so restricted for so many, but it is important to take the time to do activities that help decrease stress."

It is not unusual for nurses to care for others and neglect to care for their own needs (Bratton, 2018). This has long been a topic of discussion (Blum, 2014), and perhaps the fault of a caring and giving service profession. Nurses 
frequently neglect their own needs, when in fact one must care for oneself before caring for others. To quote one RN-BSN student,

"I know that definitely since I have become a nurse that I very rarely take the time to care for myself. I am either working, or doing schoolwork, or trying to run my household. This class has helped me so much by introducing me to yoga, something that I have always wanted to do and now I try to do some every day! It helps so much with my stress and gives me a refreshed self to deal with my other tasks for the day."

It is important to remember "the mental part of wellness also. Managing the day to day stress as a nurse is rough ... the tools we used have been wonderful in dealing with stress and anxiety ... I think I now use them every day!”

While no causality may be assumed from these outcomes, it is important to note that overall scores from pre and post-assessment did show significant changes from the start of the semester to the end of the semester, and that females did show significant increases in all twelve dimensions. And while males did not show significant increases in all twelve dimensions, scores for all twelve dimensions of wellness did show increases from the beginning of the semester to the end of semester for males as well.

\section{LIMITATIONS}

There are some limitations to this study. First, with any form of self-report there is a potential for misunderstanding the questions or misrepresentation from the participants. However, since there were no secondary gains based off the self-report it may be assumed that misrepresentation of oneself is probably minimal in this study. Second, only gender as a demographic was analyzed for pre-post scores along with overall assessments. Examining other factors such as age differences might give a clearer picture of how the wellness inventory and OAP classes affect different demographic groups in future studies. Third, there was no control group in this study, so assumptions of change as a result of the class and wellness inventory activities cannot be assumed. Future, studies should include a control group of students that have not been exposed to PED101 yet or are not currently taking a PED101 course.

\section{CONCLUSION}

This research started off exploratory in nature but yielded some very positive pre-post assessment quantitative data concerning RN-BSN students in regard to the 12 dimensions of the wellness inventory. All three null hypotheses were rejected. Overall wellness scores in all 12 dimensions showed significant increases from start of the semester to the end of the semester. Both males and females also demonstrated increases in scores of wellness from beginning of the semester to the end, with only females showing significant increases in all 12 dimensions. The results of this study suggest that having nursing students taking a PED101 course, even through an OAP context, may help improve overall wellness in this population. Nursing OAP classes that offer some form of wellness education to students may help reset or lay the foundation for effective self-care when they enter the workforce. Helping OAP students establish effective health habits when they re-enter college, may potentially help with not only overall health and wellness, but potentially play a role in helping to reduce the potential for burnout in this occupation. It is recommended that nursing programs and health educators emphasize the importance of selfcare and how it relates to other factors of health and wellbeing. 


\section{REFERENCES}

American College Health Association (2019). American College Health Association-National College Health Assessment II 2018 [Survey]. Retrieved from https://www.unthsc.edu/wellness-services/national-college-healthassessment-ii-2018

American College Health Association (2010). Healthy Campus 2010: Make it Happen. Baltimore, MD: American College Health Association:

Bart, R., Ishak, W., Ganjian, S., Jaffer, K., Abdelmesseh, M., Hanna, S., Gohar, Y., Azar, G., Vanle, B., Dang, J, \& Danovitch, I. (2018). The assessment and measurement of wellness in the clinical medical setting: A systematic review. Innovations in Clinical Neuroscience, 15(9), 14-23.

Beauvais, A.M., Stewart, J.G., DeNisco, S., \& Beauvais, J.E. (2014). Factors related to academic success among nursing students: A descriptive correlational research study. Nurse Education Today, 34(6), 918-23. https://doi.org/10.1016/j.nedt.2013.12.005

Blackboard [Computer Software]. (n.d.). Retrieved from: https://www.blackboard.com/

Blum C. A. (2014). Practicing self-care for nurses: A nursing program initiative. OJIN: The Online Journal of Issues in Nursing, 19(3), 3.

Bratton, B. (2018). Self-care for the caregiver. What are the risks if we don't care for ourselves? Journal of Pediatric Surgical Nursing, 7(1), 3. https://doi.org/10.1097/JPS.0000000000000163

Crane, P.J. \& Ward, S.F. (2016). Self-healing and self-care for nurses. AORN Journal, 104(5), 386-400. https://doi.org/10.1016/j.aorn.2016.09.007

Drew, Motter, Ross, Golial, Sharpnack, Govoni, Bozeman, \& Rababah (2016). Care for the Caregiver: Evaluation of mind-body self-care for accelerated nursing students. Holist Nursing Practice, 30(3), 148-154. https://doi.org/10.1097/HNP.0000000000000140

Ferkel, R., Judge, L., Stodden, D., \& Griffin, K. (2014). Importance of Health-Related Fitness Knowledge to Increasing Physical Activity and Physical Fitness. The Physical Educator, 71(2). Retrieved from https://js.sagamorepub.com/pe/article/view/2813

Happell, B., Dwyer, T., Reid-Searl, K., Burke, K.J., Caperchione, C.M., Gaskin, C.J. (2013). Nurses and Stress: Recognizing causes and seeking solutions. Journal of Nursing Management. 21(4), 638-647. https://doi.org/10.1111/jonm.12037

Lothes, J. (2020). Teaching Wellness in a College Physical Education Course: Pre-post Outcomes over the Semester". Building Healthy Academic Communities Journal, 4(1), 28-47. https://doi.org/10.18061/bhac.v4i1.7267

Nanney. (2019). Physical activity and wellness. TopHat: Toronto Canada.

Osam, E. K., Bergman, M., \& Cumberland, D. M. (2017). An Integrative Literature Review on the Barriers Impacting Adult Learners' Return to College. Adult Learning, 28(2), 5460. https://doi.org/10.1177/1045159516658013 
Palombi, B.J. (1992). Psychometric properties of wellness instruments. Journal of Counseling and Development, 71, 221225. https://doi.org/10.1002/j.1556-6676.1992.tb02204.x

Perfetto, L.M. (2015). Facilitating educational advancement of RNs to the Baccalaureate: What are they telling us? Nursing Ed Perspectives (National League for Nursing), 36(1), 34-41. https:/ /doi.org/10.5480/13-1161.1

Sarver, W., Cichra, N., \& Kline, M. (2015). Perceived benefits, motivators, and barriers to advancing nurse education: Removing barriers to improve success. Nursing Education Perspectives (National League for Nursing), 36(3), 153-156. https://doi.org/10.5480/14-1407

Terp, U., Hjarthag, F., \& Bisholt, B. (2019). Effects of a cognitive behavioral-based stress management program on stress management competency, self-efficacy and self-esteem experienced by nursing students. Nurse Educator, 44(1), p.E1-E5. https://doi.org/10.1097/NNE.0000000000000492

Travis, J.W. (1981). The Wellness Inventory. Mill Valley, CA. Wellness Associates

Travis, J.W., \& Ryan, R.S. (2004) Wellness workbook. Berkeley: Ten Speed Press US Department of Health and Human Services. (2018). 2018 Physical activity guidelines advisory committee scientific report.

Warren, B., \& Odenheimer Brin, E. (2017). Advancing the physical activity curriculum at the collegiate level, Health Education, 117(4), 372-381. https://doi.org/10.1108/HE-07-2016-0026

Well People Affiliates. Wellness Inventory benefits, 2018b. Retrieved May 20, 2019, from https://www.wellpeople.com/WhatIsWellness.aspx

Well People Affiliates.12 dimensions of wellness, 2018a. Retrieved May 20, 2019, from http:/ /www.wellpeople.com/WellnessDimensions.aspx

World Health Organization (2000). The World Health Report 2000. Health Systems: Improving Performance. WHO, Geneva.

Address author correspondence to:

John Lothes II, LPA, Ed.D.

Lecturer

University of North Carolina Wilmington

School of Health and Applied Human Sciences

Physical Activity and Wellness (PED 101)

601 S. College Rd.

Wilmington, NC 28403

lothesj@uncw.edu 